\title{
Low-Profile Intra-Aneurysmal Flow Disruptor WEB 17 versus WEB Predecessor Systems for Treatment of Small Intracranial Aneurysms: Comparative Analysis of Procedural Safety and Feasibility
}

\author{
(D). Goertz, (D) T. Liebig, (DE. Siebert, (D). Herzberg, (D). Pennig, (D) M. Schlamann, (D). Borggrefe, (D) B. Krischek, (D) F. Dorn, and
} (D) C. Kabbasch

\begin{abstract}
BACKGROUND AND PURPOSE: The Woven EndoBridge 17 has recently been introduced to the market for facilitated endovascular treatment of small bifurcation aneurysms $(\leq 7 \mathrm{~mm})$ with low-profile microcatheters. We compared the Woven EndoBridge 17 with its predecessor versions in terms of procedural safety and feasibility.
\end{abstract}

MATERIALS AND METHODS: This was a multicenter review of aneurysms ranging from 3 to $7 \mathrm{~mm}$ treated with the Woven EndoBridge between 2011 and 2019. Aneurysm characteristics, procedural parameters, and complications were retrospectively compared between treatment with the Woven EndoBridge 17 and a control group that was treated with its predecessor versions, using inverse probability of treatment weighting.

RESULTS: Thirty-eight aneurysms treated with a Woven EndoBridge 17 (mean size, $4.9 \pm 1.5 \mathrm{~mm}$ ) and 70 treated with a predecessor version of the Woven EndoBridge 17 (mean size, $5.6 \pm 1.4 \mathrm{~mm}$ ) were included. The predecessor version of the Woven EndoBridge 17 had a higher failure rate (10.3\%) than the Woven EndoBridge $17(0 \%, P=.05)$. Additional stent placement was performed more often with the predecessor version of the Woven EndoBridge 17 (10.0\%) than with the Woven EndoBridge 17 (2.6\%, adjusted $P=.005$ ). The predecessor version of the Woven EndoBridge 17 was associated with a higher thromboembolic event rate $(14.3 \%)$ than the Woven EndoBridge 17 (5.3\%, adjusted $P=.002$ ). Neurologic complications (Woven EndoBridge 17: 2.6\%; predecessor version of the Woven EndoBridge 17: $2.9 \%$, adjusted $P=1.0$ ) and immediate complete aneurysm occlusion rates (Woven EndoBridge 17: 57.9\%; predecessor version of the Woven EndoBridge 17: $54.3 \%$, adjusted $P=.21$ ) did not differ significantly between groups.

CONCLUSIONS: In the current study, the Woven EndoBridge 17 was associated with a potentially lower thromboembolic event rate than the predecessor version of the Woven EndoBridge 17, without compromising the immediate aneurysm occlusion rate. Long-term clinical and angiographic outcome analysis will be necessary to draw a definite conclusion.

ABBREVIATIONS: AcomA = anterior communicating artery; IPTW = inverse probability of treatment weighting; $\mathrm{pWEB}=$ predecessor version of the Woven EndoBridge 17; SL = Single-Layer; $\mathrm{WEB}=$ Woven EndoBridge

ntrasaccular flow disruption is a cutting-edge treatment option for intracranial aneurysms, in particular for wide-neck and bifurcation aneurysms, which are typically difficult to treat by standard endovascular techniques. ${ }^{1-3}$ The Woven EndoBridge

Received May 21, 2019; accepted after revision July 14

From the Department of Neuroradiology (L.G., L.P., M.S., J.B., C.K.), University Hospital of Cologne, Cologne, Germany; Center for Neurosurgery (L.G., B.K.), University of Cologne, Faculty of Medicine and University Hospital, Cologne, Germany; Department of Neuroradiology (T.L., M.H., F.D.), University Hospital Munich, Munich, Germany; and Department of Neuroradiology (E.S.), University Hospital of Berlin (Charité), Berlin, Germany.

L. Goertz and T. Liebig contributed equally to this work.

Please address correspondence to Lukas Goertz, MD, Department of Neuroradiology, University Hospital of Cologne, Kerpener Str 62, 50937 Cologne, Germany; e-mail: lukas.goertz@uk-koeln.de

http://dx.doi.org/10.3174/ajnr.A6183
(WEB; Sequent Medical, Aliso Viejo, California) is a self-expanding flow disruptor that is placed in the aneurysm sac and seals the aneurysm neck without the compelling need for supporting devices. $^{4-6}$ Its safety and efficacy have been demonstrated in several large, multicenter studies. ${ }^{7-13}$ For instance, in the Woven EndoBridge Intrasaccular Therapy (WEB-IT) study, the adverse event rate was $0.7 \%$ among 148 patients, achieving adequate aneurysm occlusion in $84.6 \%$ at 1 -year follow-up. ${ }^{14}$

Since the introduction of the Dual-Layer WEB in 2010, the WEB has been progressively refined and new systems such as the Single-Layer (SL) and Single-Layer Sphere WEBs have been introduced to the market, mainly to facilitate device deployment while maintaining good neck coverage and reducing procedural complications. ${ }^{1,15-18}$ Whereas the early-generation WEBs could be delivered through only 0.027 - to 0.033 -inch microcatheters, 
newer versions of the Single-Layer and Single-Layer Sphere types up to $7 \mathrm{~mm}$ in diameter were redesigned for delivery through a 0.021-inch microcatheter (WEB 21).

The WEB 17 is the latest generation. It is composed of fewer and thinner nitinol wires than the WEB 21 (72-108 versus 144216 wires) and comes with a new delivery wire, which has been reduced from 0.020 to 0.015 inches. ${ }^{19}$ Due to these modifications, the WEB 17 is compatible with a 0.017-inch inner-diameter microcatheter. The aim of this modification was to widen the range of applicability of the WEB, in particular for small and distally located aneurysms. To date, the WEB 17 system is available as the WEB Single-Layer (size range, $3 \times 2$ to $7 \times 4 \mathrm{~mm}$ ), which is oblong, and as the WEB Single-Layer Sphere (size range, 4$7 \mathrm{~mm}$ ), which is more spherical.

Because the introduction of the WEB 17 system is relatively recent, clinical data on its safety and feasibility profile are still limited. The objective of the current study was to present our multicenter experience in treating small aneurysms with the WEB 17 and to compare the complication rates and procedural aspects with predecessor WEB systems. To address a potential selection bias, we performed an inverse probability of treatment weighting approach using propensity scores.

\section{MATERIALS AND METHODS}

The authors retrospectively reviewed consecutive patients who underwent WEB embolization at 3 German high-volume neurovascular centers (University Hospital Cologne, University Hospital Munich and University Hospital Berlin, Charité) between January 2011 and February 2019. In accordance with the institutional guidelines, ethics committee approval was not required for this retrospective study.

\section{Inclusion and Exclusion Criteria}

All patients treated with the WEB at the 3 institutions were retrospectively reviewed. Exclusion criteria were defined as follows: 1) WEB size $>7 \mathrm{~mm}, 2$ ) aneurysm size $>7 \mathrm{~mm}, 3$ ) previously treated aneurysms, and 4) treatment of multiple aneurysms with the WEB device during a single procedure. We report on patients with failed WEB implantations; however, these aneurysms were excluded from comparative analysis of complications and procedural aspects. The enrolled patients were divided into WEB 17 and predecessor version of the WEB 17 (pWEB) groups, on the basis of whether they were treated with the WEB 17 or with predecessor WEB versions.

\section{Procedure}

After diagnosis of a ruptured or unruptured intracranial aneurysm, the case was discussed within a multidisciplinary team among vascular neurosurgeons and interventional neuroradiologists and treatment decisions were made in consensus. The use of the WEB was left to the discretion of the neurointerventionalist. In general, the WEB was used for wide-neck and bifurcation aneurysms with unfavorable configuration for endovascular coiling as a treatment alternative for stent-assisted procedures or microsurgical clipping. At all 3 centers, the neurointerventionalists were initially trained and later proctored by the same neurointerventionalist (T.L.); this procedure ensured a homogeneous treatment technique across centers.

All procedures were performed via a transfemoral approach with the patient under general anesthesia in a biplane angiosuite (Philips AlluraClarity FD 20/15, Philips Healthcare, Best, the Netherlands and Siemens Axiom Artis, Siemens, Erlangen, Germany). The WEB 17 was delivered through the dedicated VIA 17 microcatheter (Sequent Medical), and the pWEB, through dedicated larger VIA microcatheters.

The appropriate WEB size was selected according to the aneurysm width and height as measured on 2D DSA images. Implant sizes were chosen to be slightly larger than the maximum aneurysm diameter as recommended in the instructions for use. We aimed to treat all aneurysms of $<7 \mathrm{~mm}$ with the WEB only, without the use of additional intraluminal devices such as stents or flow diverters to avoid long-term antiplatelet medication. However, if the WEB tended to protrude into the parent vessel, an intracranial stent was additionally implanted at the operator's discretion. Adjunctive coiling was used in selected cases to provide optimal aneurysm occlusion.

\section{Anti-Aggregation Therapy}

For treatment of unruptured aneurysms, a bolus of heparin (5000 IU) was administered after groin puncture, followed by aliquots of $1000 \mathrm{IU} / \mathrm{h}$. Heparin was discontinued at the end of the procedure. In all patients with unruptured aneurysms, acetylsalicylic acid, $100 \mathrm{mg} /$ day, was administered 5-7 days before the procedure and continued for a minimum of 4-6 weeks. If additional stent implantation was necessary, dual antiplatelet therapy with acetylsalicylic acid, $100 \mathrm{mg}$, and clopidogrel, $75 \mathrm{mg}$, was administered for at least 4 months after the procedure. Thereafter, acetylsalicylic acid monotherapy was continued life-long. In patients with ruptured aneurysms treated with the WEB only, no antiplatelets were administered.

In scheduled cases, platelet inhibition was tested with acetylsalicylic acid and accessory P2Y12 assays when required (VerifyNow; Accumetrics, San Diego, California). A platelet inhibition level between 350 and 550 acetylsalicylic acid response units and 30\%-90\% for clopidogrel was requested. An insufficient response to either drug was counteracted by dose escalation (eg, clopidogrel, $150 \mathrm{mg} /$ day) or substitution with prasugrel (60-mg bolus, $10 \mathrm{mg} /$ day).

\section{Data Collection}

The following variables were collected retrospectively from the medical charts: patient age, sex, rupture status, World Federation of Neurosurgical Societies grading scale score, Fisher score, treatment duration, fluoroscopy time, radiation exposure, and amount of applied contrast. Procedural complications were recorded by 2 researchers (L.G., M.H.) who were not involved in aneurysm treatment. We report both symptomatic and asymptomatic events. All thromboembolic and hemorrhagic events are reported. The severity of ischemic stroke was assessed by the National Institutes of Health Stroke Scale, and any change of $\geq 1$ point was considered a complication. Adverse events associated 
Table 1: Baseline patient and aneurysm characteristics ${ }^{\mathrm{a}}$

\begin{tabular}{|c|c|c|c|c|}
\hline & $\begin{array}{l}\text { WEB } 17 \\
(n=38)\end{array}$ & $\begin{array}{c}\text { pWEB } \\
(n=70)\end{array}$ & $\begin{array}{c}P \\
\text { Value }\end{array}$ & $\begin{array}{c}\text { Adjusted } \\
P \text { Value }\end{array}$ \\
\hline Patient age (yr) & $55.7 \pm 12.7$ & $57.3 \pm 12.2$ & .54 & .72 \\
\hline Female sex & 25 (65.8\%) & $52(74.3 \%)$ & .35 & .61 \\
\hline Ruptured aneurysms & $10(26.3 \%)$ & $24(34.3 \%)$ & .39 & .59 \\
\hline WFNS I & $2(5.3 \%)$ & 10 (14.3\%) & .82 & .06 \\
\hline WFNS II & $2(5.3 \%)$ & $3(4.3 \%)$ & & \\
\hline WFNS III & $2(5.3 \%)$ & $4(5.7 \%)$ & & \\
\hline WFNS IV & $1(2.6 \%)$ & $2(2.9 \%)$ & & \\
\hline WFNS V & $3(7.9 \%)$ & $5(7.1 \%)$ & & \\
\hline Fisher 1 & $1(2.6 \%)$ & $2(2.9 \%)$ & .77 & .30 \\
\hline Fisher 2 & $0(0 \%)$ & $2(2.9 \%)$ & & \\
\hline Fisher 3 & $3(7.9 \%)$ & $5(7.1 \%)$ & & \\
\hline Fisher 4 & $6(15.8 \%)$ & $13(18.6 \%)$ & & \\
\hline \multicolumn{5}{|l|}{ Aneurysm location } \\
\hline AcomA & $14(36.8 \%)$ & $15(21.4 \%)$ & .08 & .92 \\
\hline Pericallosal & $0(0 \%)$ & $1(1.4 \%)$ & 1.0 & .24 \\
\hline MCA & $4(10.5 \%)$ & 15 (21.4\%) & .19 & .60 \\
\hline \multicolumn{5}{|l|}{ ICA } \\
\hline Paraophthalmic & $1(2.6 \%)$ & 7 (10.0\%) & .26 & .06 \\
\hline PcomA & $4(10.5 \%)$ & $5(7.1 \%)$ & .72 & .55 \\
\hline Terminus & $3(7.9 \%)$ & $0(0 \%)$ & .04 & .25 \\
\hline BA & $9(23.7 \%)$ & $24(34.3 \%)$ & .25 & .82 \\
\hline SUCA & $1(2.6 \%)$ & $0(0 \%)$ & .35 & .01 \\
\hline PICA & $2(5.3 \%)$ & $3(4.3 \%)$ & 1.0 & .53 \\
\hline Anterior circulation & $26(68.4 \%)$ & $43(61.4 \%)$ & .47 & .63 \\
\hline Posterior circulation & $12(31.6 \%)$ & 27 (38.6\%) & & \\
\hline Bifurcation location & 27 (71.1\%) & $54(77.1 \%)$ & .49 & .72 \\
\hline Aneurysm size (mm) & $4.9 \pm 1.5$ & $5.6 \pm 1.4$ & .007 & .55 \\
\hline Neck width $(\mathrm{mm})$ & $3.6 \pm 1.1$ & $4.2 \pm 1.3$ & .04 & .95 \\
\hline $\mathrm{D} / \mathrm{N}$ ratio & $1.4 \pm 0.5$ & $1.4 \pm 0.4$ & .56 & .90 \\
\hline Wide neck & 35 (92.1\%) & $65(92.9 \%)$ & 1.0 & .66 \\
\hline
\end{tabular}

Note:-WFNS indicates World Federation of Neurosurgical Societies grading scale; D/N ratio, dome-to-neck ratio; PcomA, posterior communicating artery; BA, basilar apex; SUCA, superior cerebellar artery.

${ }^{a}$ Data are number and percentage of means.

with persisting neurologic deficits at discharge were defined as neurologic complications.

\section{Angiography}

Baseline conventional 4-vessel DSA scans were reviewed to determine aneurysm size, aneurysm neck width, and dome-to-neck ratio. Wide-neck aneurysms were defined as having a neck width of $\geq 4 \mathrm{~mm}$ and/or a dome-to-neck ratio of $\leq 2$.

The Raymond-Roy occlusion classification was used to evaluate immediate aneurysm occlusion after WEB implantation: 1) complete occlusion, 2) neck remnant, and 3) aneurysm remnant. Complete occlusion and neck remnants were defined as adequate occlusion. Immediate aneurysm occlusion was assessed independently on the basis of 2D-DSA by 3 consultant neuroradiologists (C.K., E.S., F.D.). Discrepancies were resolved in consensus.

\section{Statistical Analysis}

Quantitative data were presented as numbers and percentages and analyzed with the $\chi^{2}$ and Fisher exact tests. Quantitative data were presented as means with SDs and tested for normality using the Shapiro-Wilk test. Groups were compared using the unpaired $t$ test (normally distributed data) or the Mann-Whitney $U$ test (non-normally distributed data). Bivariate correlation analysis was performed using the Pearson and Spearman correlation coefficients. To account for a potential selection bias, we performed an inverse probability of treatment weighting (IPTW) approach based on the propensity score model. IPTW was used as a statistical technique to create 2 synthetic study groups with comparable propensity scores, in which treatment assignment was independent of measured baseline characteristics. This method aimed to minimize a potential selection bias and to obtain comparative estimates of treatment effects. Propensity scores were calculated using a multivariate logistic regression model with the WEB 17 treatment as the response and the following covariates: patient age, sex, ruptured/unruptured status, aneurysm location, aneurysm size, and neck width. Statistical analysis was performed using SPSS Statistics for Windows, Version 25.0 (IBM, Armonk, New York). A $P$ value $<.05$ was considered as statistically significant.

\section{RESULTS \\ Patient and Aneurysm Characteristics}

Among 165 aneurysms treated during the study period, 108 aneurysms in 108 patients met our inclusion criteria and were enrolled. Fifty-seven aneurysms were excluded for the following reasons: WEB size of $>7 \mathrm{~mm}(n=30)$, aneurysm size of $>7 \mathrm{~mm}(n=11)$, failed WEB implantation $(n=8)$, treatment of recurrent aneurysms $(n=6)$, and treatment of multiple aneurysms with the WEB during 1 procedure $(n=2)$. The mean patient age was $56.7 \pm 12.3$ years (range, $21-87$ years), and 77 patients $(71.3 \%)$ were women. Thirty-four patients $(31.5 \%)$ were treated for ruptured aneurysms, and 74 (68.5\%), for unruptured aneurysms. The aneurysms were most frequently located at the basilar artery tip $(33,30.6 \%)$, followed by the anterior communicating artery (AcomA) $(29,26.9 \%)$, and the middle cerebral artery $(19,17.6 \%)$. The mean aneurysm size was $5.3 \pm 1.5 \mathrm{~mm}$ (range, $3-7 \mathrm{~mm}$ ), and the mean neck width was $4.0 \pm 1.2 \mathrm{~mm}$ (range, $1.5-7.2 \mathrm{~mm}$ ). A total of 100 aneurysms (92.6\%) were classified as wide-neck.

Of 108 aneurysms, 38 were treated with the WEB 17 (35.2\%) and 70 with pWEBs (64.8\%). In the pWEB group, 64 patients were treated with a 0.021 -inch microcatheter, and 6, with a 0.027 -inch microcatheter. Baseline patient and aneurysm characteristics were comparable between the 2 groups, except for a larger aneurysm size (WEB 17: $4.9 \pm 1.5 \mathrm{~mm}$; pWEB: $5.6 \pm 1.4 \mathrm{~mm}, P=.007$ ) and a wider neck (WEB 17: $3.6 \pm 1.1 \mathrm{~mm}$; pWEB: $4.2 \pm 1.3 \mathrm{~mm}, P=.042$ ) in the pWEB group, as outlined in Table 1 . To address this selection bias, we performed an IPTW adjustment approach based on the 
Table 2: Procedural specifics ${ }^{a}$

\begin{tabular}{lcccc}
\hline & $\begin{array}{c}\text { WEB 17 } \\
(\boldsymbol{n}=\mathbf{3 8})\end{array}$ & $\begin{array}{c}\text { pWEB } \\
(\boldsymbol{n}=\mathbf{7 0})\end{array}$ & $\begin{array}{c}\boldsymbol{P} \\
\text { Value }\end{array}$ & $\begin{array}{c}\text { Adjusted } \\
\boldsymbol{P} \text { Value }\end{array}$ \\
\hline WEB type & & & & \\
$\quad$ DL & $0(0 \%)$ & $6(8.6 \%)$ & .09 & .003 \\
SL & $31(81.6 \%)$ & $46(65.7 \%)$ & .08 & .001 \\
$\quad$ SLS & $7(18.4 \%)$ & $18(25.7 \%)$ & .39 & .02 \\
WEB only & $36(94.7 \%)$ & $62(88.6 \%)$ & .49 & .02 \\
Additional coiling & $1(2.6 \%)$ & $1(1.4 \%)$ & 1.0 & 1.0 \\
Additional stents & $1(2.6 \%)$ & $7(10.0 \%)$ & .26 & .005 \\
Treatment duration $(\mathrm{min})$ & $122 \pm 67$ & $133 \pm 67$ & .48 & .007 \\
Fluoroscopy time $(\mathrm{min})$ & $25.4 \pm 20.1$ & $27.6 \pm 23.3$ & .77 & .02 \\
Radiation dose $\left(\mathrm{cGy} \times \mathrm{cm}^{2}\right)$ & $10,319 \pm 7108$ & $11,899 \pm 9142$ & .55 & .03 \\
Contrast $(\mathrm{mL})$ & $151 \pm 68$ & $145 \pm 72$ & .59 & .70 \\
\hline
\end{tabular}

Note:-DL indicates Dual-Layer; SLS, Single-Layer Sphere.

${ }^{a}$ Data are number and percentage of means.

Table 3: Immediate angiographic results

\begin{tabular}{|c|c|c|c|c|}
\hline & $\begin{array}{l}\text { WEB } 17 \\
(n=38) \\
\end{array}$ & $\begin{array}{c}\text { pWEB } \\
(n=70)\end{array}$ & $P$ Value & $\begin{array}{c}\text { Adjusted } \\
P \text { Value }\end{array}$ \\
\hline Complete occlusion (RROC 1) & $22(57.9 \%)$ & $38(54.3 \%)$ & .55 & .21 \\
\hline Neck remnant (RROC 2) & $8(21.1 \%)$ & $11(15.7 \%)$ & & \\
\hline Aneurysm remnant (RROC 3) & $8(21.1 \%)$ & $21(30.0 \%)$ & & \\
\hline
\end{tabular}

Note:-RROC indicates Raymond-Roy occlusion classification.

\begin{tabular}{lcccc}
\hline & $\begin{array}{c}\text { WEB 17 } \\
(\boldsymbol{n}=38)\end{array}$ & $\begin{array}{c}\text { PWEB } \\
(\boldsymbol{n}=70)\end{array}$ & $\begin{array}{c}\boldsymbol{P} \\
\text { Value }\end{array}$ & $\begin{array}{c}\text { Adjusted } \\
\boldsymbol{P} \text { Value }\end{array}$ \\
\hline Thromboembolic events & $2(5.3 \%)$ & $10(14.3 \%)$ & .21 & .002 \\
Ischemic stroke & $1(2.6 \%)$ & $5(7.1 \%)$ & .42 & .06 \\
Hemorrhagic complications & $2(5.3 \%)$ & $1(1.4 \%)$ & .28 & .37 \\
Neurologic complications & $1(2.6 \%)$ & $2(2.9 \%)$ & 1.0 & 1.0 \\
\hline
\end{tabular}

Table 4: Procedure-related complications

2.6\%). This difference was not significant in the unweighted analysis $(P=.256)$ but became significant after IPTW adjustment $(P=.005)$.

The smallest WEB 17 version, the WEB SL $3 \times 2 \mathrm{~mm}$, was used for treatment of 3 small wide-neck aneurysms with a maximum diameter ranging from 3 to $3.3 \mathrm{~mm}$. The aneurysms were located at the AcomA, the basilar apex, and the M1 segment of the MCA, respectively. Navigation and delivery of the WEB were smooth in all cases, resulting in immediate complete occlusion in 2 cases and 1 neck remnant, without any incidence of adverse events. In a fourth case, a 7-mm large, bilobed AcomA aneurysm was treated, and the WEB SL $3 \times 2$ was used to occlude 1 aneurysm lobe, while the second lobe was embolized with 3 coils.

The average treatment duration was $128 \pm 67$ minutes, $122 \pm$ 67 minutes for the WEB 17 and $133 \pm 67$ minutes for WEB controls $(P=.475)$. The mean fluoroscopy time was $26.8 \pm 22.2$ minutes, $25.4 \pm 20.1$ minute for the WEB 17 and $27.6 \pm 23.3$ minutes for the pWEB $(P=.765)$. The mean propensity score model, achieving comparable groups regarding all baseline characteristics (Table 1).

\section{Aneurysm Treatment}

Procedural specifics are detailed in Table 2. Implantation of the WEB 17 was technically successful in all aneurysms (38/ $38,100 \%)$, compared with 8 treatment failures in the pWEB group $(8 / 78,10.3 \%, P=.052)$. Failed WEB implantation was recorded at the anterior communicating artery $(n=3)$, paraophthalmic regions of the internal carotid artery $(n=3)$, middle cerebral artery bifurcation $(n=1)$, and basilar apex $(n=1)$. The mean aneurysm size ranged from 3.3 to $6.9 \mathrm{~mm}$. Reasons for failed implantation were WEB protrusion with impeded blood flow $(n=3)$, WEB malposition $(n=3)$, and delivery failure due to a sharp aneurysm angle in sidewall aneurysms $(n=2)$. Aneurysms with failed WEB implantation were excluded from further analysis as stated above. Of 108 included aneurysms, 98 (90.7\%) were treated by the WEB only, 36 $(94.7 \%)$ were in the WEB 17 group, and 62 (88.6\%) were in the pWEB group $(P=.489)$. In both groups, adjunctive coils were used in 1 patient to achieve immediate complete aneurysm occlusion, respectively. Additional stent placement was performed more often after implantation of predecessor WEBs $(7 / 70,10.0 \%)$ than after embolization with the WEB $17(1 / 38$, radiation dose was $11331 \pm 8466 \mathrm{cGy} \times \mathrm{cm}^{2}, 10319 \pm$ $7108 \mathrm{cGy} \times \mathrm{cm}^{2}$ for the WEB 17 and $11899 \pm 9142 \mathrm{cGy} \times \mathrm{cm}^{2}$ for the pWEB $(P=.552)$. On average, $146 \pm 70 \mathrm{~mL}$ of contrast was used, $151 \pm 68 \mathrm{~mL}$ for the WEB 17 and $145 \pm 72 \mathrm{~mL}$ for the pWEB $(P=.585)$. After IPTW adjustment, treatment with the WEB 17 was associated with significantly shorter treatment duration $(P=.007)$, shorter fluoroscopy time $(P=.016)$, and reduced radiation exposure $(P=.031)$ compared with predecessor WEBs.

Bivariate correlation analysis showed no significant correlation between treatment date and treatment duration $(r=-0.08$, adjusted $P=.36)$ and radiation exposure $(r=-0.05$, adjusted $P=.5)$.

\section{Angiographic Outcome}

Immediate complete occlusion after WEB implantation was obtained in 60 aneurysms (55.6\%); neck remnants, in 19 (17.6\%); and aneurysm remnants, in 29 (26.9\%). Immediate occlusion rates were not significantly different between both treatment groups, either in the unweighted $(P=.55)$ or the weighted analysis $(P=.21)$ (Table 3$)$.

Procedural complications are detailed in Table 4. In the WEB 17 group, there were 2 thromboembolic events (5.3\%). In the first

\section{Complications}


case, a patient was treated for a ruptured PICA aneurysm. After the procedure, the patient had transient hemianopsia. The CT scan showed a partial posterior infarction of the posterior cerebral artery, which occurred most likely due to thromboembolism during WEB placement. In the second patient, implantation of a WEB into an unruptured AcomA aneurysm resulted in stenosis of the left A2 segment, which could be reopened by additional stent implantation. The patient did not have any symptoms after the procedure.

Furthermore, there were 2 hemorrhagic events (5.3\%) related to the WEB 17 implantation. The first patient was treated for an unruptured aneurysm and had a subarachnoid hemorrhage from a proximal perforating artery, which probably ruptured due to manipulation of the microwire. The patient was discharged to a rehabilitation center with persisting mild hemiparesis. In the second case, perforation of an unruptured AcomA aneurysm occurred during device delivery; however, the bleeding was stopped immediately by WEB implantation and the patient did not have any symptoms.

The overall neurologic complication rate after WEB 17 implantation was $2.6 \%$, and there was no procedure-related mortality.

The WEB 17 was associated with a lower thromboembolic event rate (5.3\%) compared with the pWEB (14.3\%, $P=.208)$. After adjustment for the propensity score, this difference was statistically significant $(P=.002)$. Moreover, there was a borderline significant trend toward a higher ischemic stroke rate after pWEB placement in the weighted analysis $(P=.055)$. In the subgroup analysis of the pWEB group, thromboembolic events occurred tendentially more often in ruptured aneurysms $(25 \%$, $6 / 24)$ than in unruptured aneurysms $(8.9 \%, 4 / 46, P=.08)$. The neurologic complication rate was similar between both groups (WEB 17: 2.6\%; pWEB: $2.9 \% ; P=1.0$, adjusted $P=1.0$ ).

\section{DISCUSSION}

In the current study, we evaluated the treatment of small aneurysms $(\leq 7 \mathrm{~mm})$ with the new low-profile WEB 17 and compared the results with predecessor WEB systems. To produce reliable results and to address a potential selection bias, we performed a separate IPTW analysis using propensity scores.

Small aneurysms located at a bifurcation represent a technical challenge for endovascular therapy, even when using the WEB device. $^{20}$ Moreover, the WEB is difficult to deliver to distally located aneurysms because it requires deployment by a relatively large microcatheter.

The WEB 17 consists of a reduced number of nitinol wires and can be delivered through a VIA 17 microcatheter, which is less rigid than the predecessor VIA 21. The flexible design of the WEB 17 system facilitates navigation through tortuous vessels and sharp-angled branching points. Besides navigation to more distally located aneurysms, reducing the delivery diameter of the WEB system may also facilitate the treatment of sidewall aneurysms, which can be difficult to treat with the more rigid 0.021 inch system. In a previous study on ICA sidewall aneurysms, we reported deployment failure due to malrotation of the device after delivery of the pWEB in 2 aneurysms with sharp aneurysm angles. ${ }^{21}$ Because WEB positioning could not be improved, the
WEBs were finally removed and the aneurysms were treated with standard coiling. We speculate that treatment of these aneurysms would have been possible with the low-profile WEB 17.

In our study, WEB 17 implantation was technically successful in all cases. In contrast, there were 8 treatment failures in the WEB 21 group (10.3\%). Although this difference might be partially related to increased operator experience during WEB 17 implantation, it indicates the high feasibility of WEB 17 treatment.

To date, there are 2 available studies on the WEB 17. Van Rooij et $\mathrm{al}^{19}$ analyzed 46 aneurysms and reported a technical success rate of $100 \%$. Similar technical success was reported by Mihalea et $\mathrm{al}^{22}$ in a study of 28 aneurysms. Both authors reported that handling the WEB 17 was smoother compared with predecessor versions and required less push and pull forces. However, the authors also acknowledged that the WEB 17 is more susceptible to deformation during delivery because it has fewer and thinner nitinol wires, resulting in a weaker structure and shape retention. These properties can result in malposition and neck remnants after delivery, which may require WEB repositioning and repeat deployment. Thus, Mihalea et al recommended validating the WEB position with VasoCT (Philips Healthcare) immediately after deployment. ${ }^{22}$

Our data corroborate the subjective ease of navigation and deployment of the WEB 17. Generally, positioning the WEB 17 was feasible, as reflected by a $100 \%$ technical success rate and a reduced use of intracranial stents, which were typically implanted if a WEB protruded into the parent vessel lumen. In our experience, repositioning the WEB 17 was not generally necessary, and immediate angiographic results were comparable with those with the predecessor WEB systems. Our results indicated that treatment with the WEB 17 was associated with reduced treatment duration, fluoroscopy time, and radiation exposure, which became significant after IPTW adjustment. Although we could not show a significant correlation between treatment date and treatment duration or radiation exposure, the differences in additional stent implantation and shorter treatment duration may be, in part, attributed to increasing operator experience during the study period, thus potentially favoring the WEB 17 group. However, in our experience, the WEB 17 system is more flexible and has a better conformability than the predecessor versions. Due to a comparably rigid design of the nitinol wires, the predecessor WEBs might have been more likely to protrude into the parent artery, in particular in cases in which the aneurysm axis deviates greatly from the vessel axis. In contrast, we observed that the WEB 17 generally adapts to the aneurysm wall very smoothly, showing a lower tendency to alter aneurysm geometry and to cause parent artery stenosis. Although a direct statistical comparison is difficult, our data support the impression that navigation and deployment of the WEB 17 may be smoother than in the predecessor WEB versions.

In the present study, we treated 3 very small aneurysms on the order of $3 \mathrm{~mm}$ with the new WEB SL $3 \times 2 \mathrm{~mm}$. Two were located at a bifurcation; and 1, at the M1 segment. In all cases, the device could be deployed smoothly, and adverse events did not occur. Immediate angiographic control showed complete occlusion in 2 cases and a neck remnant in the third case. 
Thromboembolism is considered the most prevalent event related to WEB implantation. ${ }^{18}$ Muskens et $\mathrm{al}^{23}$ performed a meta-analysis on 718 aneurysms treated with the WEB before the introduction of the WEB 17 system and reported a thromboembolic event rate of $10.3 \%$. Because most thromboembolic events remain asymptomatic, the WEB constitutes a safe treatment option with major morbidity and mortality as low as $3 \%$ and $2 \%$, respectively. ${ }^{24}$ In the current study, the safety results of the WEB control group are within the range cited previously, with thromboembolic events occurring in $14.3 \%$ and neurologic complications in $2.9 \%{ }^{15,18,23}$

In the comparative analysis, the thromboembolic event rate in the WEB 17 group was 5.3\% and thus was much lower than in the WEB control group. This might be, in part, related to a smaller portion of aneurysms treated in combination with intracranial stents. Beyond that, a lower profile of all materials used, ease of use, and shorter procedure times associated with the WEB 17 system favor reducing the potential for thromboembolic events. Among intracranial stents and flow diverters, several in vivo and ex vivo studies have already suggested that miniaturization of the stent design and the delivery system may reduce the thrombogenicity of the device. ${ }^{25-28}$ Hence, miniaturization of the WEB system might also contribute to reduced thrombogenicity of the system. Moreover, we observed that the WEB 17 showed a reduced tendency to protrude into the parent vessel, though we did not quantify this aspect. Finally, a slightly higher portion of ruptured cases in the pWEB group may also contribute to a higher thromboembolic event rate. ${ }^{29}$

In previous studies, similar results were obtained. The thromboembolic event rate was $4 \%$ in the study by Mihalea et $\mathrm{al}^{22}$ and $5 \%$ in the study by van Rooij et al. ${ }^{19}$

These findings collectively suggest a high procedural safety profile of the WEB 17 system. Because treatment of small bifurcation aneurysms proved to be highly efficacious and could be achieved more smoothly than with predecessor WEB versions, we believe the WEB 17 system is a highly valuable adjunct to the neurointerventional armamentarium, and we have been using the WEB 17 exclusively for small aneurysms of $<7 \mathrm{~mm}$. Additional studies will be required to further expand the indications of the WEB 17.

\section{Limitations}

Our study has several limitations. Although we performed a multicenter study, the sample size was only moderate and data were collected retrospectively, making a generalization of the data difficult. To mitigate this limitation in part and to minimize a potential selection bias, we performed an IPTW approach based on propensity scores. Patients were not consecutive but were selected on the basis of the mentioned inclusion criteria and the anticipated suitability for WEB treatment. Because the introduction of the WEB 17 is relatively recent, angiographic follow-up is incomplete and was not reported in the current study. A further limitation is that aneurysm occlusion was not determined by a core laboratory, which might bias the interpretation of the angiographic results. ${ }^{30}$ To reduce this potential bias at least in part, all angiographic images were assessed blinded and independently by 3 experienced consultant neurointerventionalists (C.K., F.D.,
E.S.). Discrepancies were resolved by consensus. Finally, increased operator experience may have favored the WEB 17 group in terms of complication rates and treatment duration.

\section{CONCLUSIONS}

Deployment of the new low-profile WEB 17 in small aneurysms was generally smooth and required less stent assistance than the predecessor WEB versions. The VIA 17 facilitates microcatheter navigation toward the target vessel, especially in situations with a complex vascular anatomy. If procedural time and the amount of radiation exposure can be used as surrogate parameters to measure ease of use, then the WEB 17 is a definite improvement over the pWEB. Finally, the thromboembolic event rate of the WEB 17 was lower compared with predecessor WEBs, seemingly without compromising treatment efficacy. These features make the WEB 17 a valuable adjunct to the existing WEB range and expand indications to very small aneurysms.

\section{REFERENCES}

1. Sivan-Hoffmann R, Gory B, Riva R, et al. One-year angiographic follow-up after WEB-SL endovascular treatment of wide-neck bifurcation intracranial aneurysms. AJNR Am J Neuroradiol 2015;36: 2320-24 CrossRef Medline

2. Lubicz B, Mine B, Collignon L, et al. WEB device for endovascular treatment of wide-neck bifurcation aneurysms. AJNR Am J Neuroradiol 2013;34:1209-14. CrossRef Medline

3. Pierot L, Klisch J, Liebig T, et al. WEB-DL endovascular treatment of wide-neck bifurcation aneurysms: long-term results in a European series. AJNR Am J Neuroradiol 2015;36:2314-19 CrossRef Medline

4. Ding Y, Lewis D, Kadirvel R, et al. The Woven EndoBridge: a new aneurysm occlusion device. AJNR Am J Neuroradiol 2011;32:607-11 CrossRef Medline

5. Kabbasch C, Goertz L, Siebert E, et al. WEB embolization versus stent-assisted coiling: comparison of complication rates and angiographic outcomes. J Neurointerv Surg 2019;11:812-16 CrossRef Medline

6. Kabbasch C, Goertz L, Siebert E, et al. Comparison of WEB embolization and coiling in unruptured intracranial aneurysms: safety and efficacy based on a propensity score analysis. World Neurosurg 2019 Mar 9. [Epub ahead of print] CrossRef Medline

7. Fiorella D, Molyneux A, Coon A, et al. Demographic, procedural and 30-day safety results from the WEB Intra-saccular Therapy Study (WEB-IT). J NeuroIntervent Surg 2017;40:1191-96 CrossRef Medline

8. Pierot L, Gubucz I, Buhk J, et al. Safety and efficacy of aneurysm treatment with the WEB: results of the WEBCAST 2 study. AJNR Am J Neuroradiol 2017;38:1151 CrossRef Medline

9. Pierot L, Costalat V, Moret J, et al. Safety and efficacy of aneurysm treatment with WEB: results of the WEBCAST study. J Neurosurg 2016;124:1250-56 CrossRef Medline

10. Pierot L, Moret J, Turjman F, et al. WEB treatment of intracranial aneurysms: clinical and anatomic results in the French Observatory. AJNR Am J Neuroradiol 2016;37:655-59 CrossRef Medline

11. Goertz L, Liebig T, Siebert E, et al. Risk factors of procedural complications related to Woven EndoBridge (WEB) embolization of intracranial aneurysms. Clin Neuroradiol 2019 Feb 7. [Epub ahead of print] CrossRef Medline

12. Kabbasch C, Goertz L, Siebert E, et al. Factors that determine aneurysm occlusion after embolization with the Woven EndoBridge (WEB). J Neurointerv Surg 2018 Feb 7. [Epub ahead of print] CrossRef Medline 
13. Kabbasch C, Goertz L, Siebert E, et al. Treatment strategies for recurrent and residual aneurysms after Woven Endobridge implantation. J Neurointerv Surg 2018;11:390-95 CrossRef Medline

14. Arthur AS, Molyneux A, Coon AL, et al. The safety and effectiveness of the Woven EndoBridge (WEB) system for the treatment of wide-necked bifurcation aneurysms: final 12-month results of the pivotal WEB Intrasaccular Therapy (WEB-IT) Study. J Neurointerv Surg 2019 Apr 16. [Epub ahead of print] CrossRef Medline

15. Lawson A, Molyneux A, Sellar R, et al. Safety results from the treatment of 109 cerebral aneurysms using the Woven EndoBridge technique: preliminary results in the United Kingdom. J Neurosurg 2018;128:144-53 CrossRef Medline

16. Pierot L, Moret J, Turjman F, et al. WEB treatment of intracranial aneurysms: feasibility, complications, and 1-month safety results with the WEB DL and WEB SL/SLS in the French Observatory. AJNR Am J Neuroradiol 2015;36:922-27 CrossRef Medline

17. Popielski J, Berlis A, Weber W, et al. Two-center experience in the endovascular treatment of ruptured and unruptured intracranial aneurysms using the WEB device: a retrospective analysis. AJNR Am J Neuroradiol 2018;39:111-17 CrossRef Medline

18. Tau N, Sadeh-Gonik U, Aulagner G, et al. The Woven EndoBridge (WEB) for endovascular therapy of intracranial aneurysms: update of a systematic review with meta-analysis. Clin Neurol Neurosurg 2018;166:110-15 CrossRef Medline

19. van Rooij S, Peluso J, Sluzewski M, et al. The new low-profile WEB 17 system for treatment of intracranial aneurysms: first clinical experiences. AJNR Am J Neuroradiol 2018;39:859-63 CrossRef Medline

20. Asnafi S, Rouchaud A, Pierot L, et al. Efficacy and safety of the Woven EndoBridge (WEB) device for the treatment of intracranial aneurysms: a systematic review and meta-analysis. AJNR Am J Neuroradiol 2016;37:2287-92 CrossRef Medline

21. Goertz L, Liebig T, Siebert E, et al. Extending the indication of Woven EndoBridge (WEB) embolization to internal carotid artery aneurysms: a multicenter safety and feasibility study. World Neurosurg 2019 Mar 12. Epub ahead of print] CrossRef Medline

22. Mihalea C, Caroff J, Pagiola I, et al. Safety and efficiency of the fifth generation Woven EndoBridge device. J NeuroInterv Surg 2019; 11:511-15 CrossRef Medline

23. Muskens IS, Senders JT, Dasenbrock HH, et al. The Woven Endobridge device for treatment of intracranial aneurysms: a systematic review. World Neurosurg 2017;98:809-17.el CrossRef Medline

24. Lv X, Zhang Y, Jiang W. Systematic review of Woven EndoBridge for wide-necked bifurcation aneurysms: complications, adequate occlusion rate. World Neurosurg 2018;110:20-25 CrossRef Medline

25. Kraus B, Goertz L, Turowski B, et al. Safety and efficacy of the Derivo Embolization Device for the treatment of unruptured intracranial aneurysms: a multicentric study. J NeuroInterv Surg 2019;11:68-73 CrossRef Medline

26. Ley D, Mühl-Benninghaus R, Yilmaz U, et al. The Derivo embolization device, a second-generation flow diverter for the treatment of intracranial aneurysms, evaluated in an elastase-induced aneurysm model. Clin Neuroradiol 2017;27:335-43 CrossRef Medline

27. Jankowitz BT, Hanel R, Jadhav AP, et al. Neuroform Atlas Stent System for the treatment of intracranial aneurysm: primary results of the Atlas Humanitarian Device Exemption cohort. J NeuroInterv Surg 2019;11:801-06 CrossRef Medline

28. Brassel F, Grieb D, Meila D, et al. Endovascular treatment of complex intracranial aneurysms using Acandis Acclino stents. $J$ Neurointerv Surg 2017;9:854-59 CrossRef Medline

29. Liebig T, Kabbasch C, Strasilla C, et al. Intrasaccular flow disruption in acutely ruptured aneurysms: a multicenter retrospective review of the use of the WEB. AJNR Am J Neuroradiol 2015;36:1721-27 CrossRef Medline

30. Rezek I, Lingineni R, Sneade M, et al. Differences in the angiographic evaluation of coiled cerebral aneurysms between a core laboratory reader and operators: results of the Cerecyte Coil Trial. AJNR Am J Neuroradiol 2014;35:124-27 CrossRef Medline 